\title{
Natural light exposure and delirium in ICU: does the dark side cloud everything?
}

\author{
Romain Sonneville $e^{1,2^{*}} \mathbb{D}$, Roland Smonig ${ }^{2}$, Claire Dupuis ${ }^{3,4}$, Lila Bouadma ${ }^{2,4}$, Etienne de Montmollin 2,4 \\ and Jean-François Timsit ${ }^{2,4}$
}

\section{Letter to the editor \\ Dear Editor,}

We read with interest the comments of Vahedian-Azimi and colleagues about our study [1]. In our study, antipsychotics (i.e., haloperidol) were given in 32/179 (18\%) patients developing severe agitation during ICU stay. Unfortunately, doses of haloperidol were not part of study outcomes and were therefore not collected.

Based on a retrospective secondary analysis of a multicenter cohort of patients with acute respiratory distress syndrome, Vahedian-Azimi and colleagues report a higher delirium incidence in patients exposed only to artificial light during ICU stay, as compared to patients admitted to a room with windows, allowing exposure to natural light [2]. This association was observed both in crude analyses and after adjustment for common delirium risk factors. The authors accurately state that differences observed between their observations and others, including our study, may be explained by several methodological issues, likely contributing to outcome heterogeneity. Of note, reduced exposure to natural light may indeed be more detrimental in specific subgroups of patients, such as patients with ARDS or sepsis at admission, who often require a prolonged stay in the ICU. A previous study indeed suggested reduced mortality associated with natural light exposure via windows in medical patients with ICU stay greater than $72 \mathrm{~h}$ [3]. In our study, admission to a single room with potential exposure

\footnotetext{
*Correspondence: romain.sonneville@aphp.fr

2 Department of Intensive Care Medicine and Infectious Diseases, AP-HP, Bichat-Claude Bernard Hospital, 46 Rue Henri Huchard, 75018 Paris Cedex, France

Full list of author information is available at the end of the article
}

to natural light via windows (LIGHT group) was not associated with reduced delirium incidence, as compared to admission to a single room without windows (DARK group). However, natural light exposure was associated with a reduced risk of hallucinations and severe agitation episodes. A secondary exploratory analysis of our data in specific subgroups defined at ICU admission (i.e., medical admission, sepsis, and hypoxemia, defined by a $\mathrm{PaO}_{2} / \mathrm{FiO}_{2}$ ratio $<300$ ) is presented in Fig. 1. In subgroup analyses, we found heterogeneity in the effect of LIGHT as compared with DARK on delirium between patients with different types of ICU admission. There was also heterogeneity in the effect of LIGHT as compared with DARK on hallucinations between patients with sepsis and patients without sepsis, and between patients with hypoxemia and patients without hypoxemia at ICU admission.

The effects of exposure to natural light via windows on delirium burden and outcomes may be clouded by several factors that should be systematically evaluated. These not only include patients' characteristics and severity of illness at admission, but also environmental factors such as noise and interventions during ICU stay, including the use of sedative drugs and physical restraints. Moreover, illuminance in rooms may be dependent on daytime and seasons.

Further research evaluating the effect of natural light exposure in the ICU on outcomes should focus on delirium phenotypes and should also investigate other important patient-centered outcomes, such as anxiety/ depression, functional recovery and ICU memories in survivors.
SpringerOpen

(c) The Author(s) 2020. This article is licensed under a Creative Commons Attribution 4.0 International License, which permits use, sharing, adaptation, distribution and reproduction in any medium or format, as long as you give appropriate credit to the original author(s) and the source, provide a link to the Creative Commons licence, and indicate if changes were made. The images or other third party material in this article are included in the article's Creative Commons licence, unless indicated otherwise in a credit line to the material. If material is not included in the article's Creative Commons licence and your intended use is not permitted by statutory regulation or exceeds the permitted use, you will need to obtain permission directly from the copyright holder. To view a copy of this licence, visit http://creativeco mmons.org/licenses/by/4.0/. 


\section{a Delirium}

$\begin{array}{lrr}\text { Subgroup } & \text { Dark } & \text { Light } \\ \text { Admission type } & & \\ \quad \text { Medical } & 31 / 47 & 49 / 75 \\ \text { Surgical } & 24 / 30 & 16 / 27 \\ \text { Sepsis } & & \\ \text { Yes } & 37 / 50 & 47 / 68 \\ \text { No } & 18 / 27 & 18 / 34 \\ \text { PaO2/FiO2 at admission } & \\ \geq 300 & 16 / 26 & 21 / 37 \\ <300 & 37 / 51 & 44 / 65\end{array}$

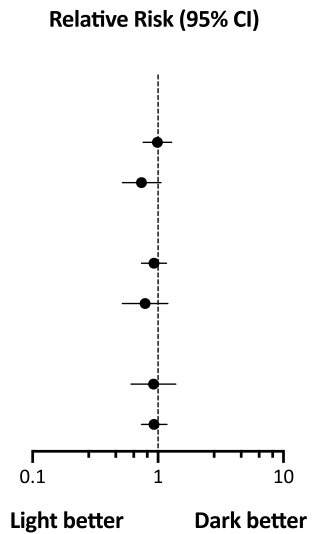

$P$ value for

heterogeneity

0.03

$0.99(0.76-1.29)$

$0.74(0.52-1.06)$

0.54

$0.93(0.74-1.17)$

$0.79(0.52-1.20)$

$0.92(0.61-1.39)$

$0.93(0.74-1.18)$

0.80

Light better Dark better

\section{b Hallucinations}

$\begin{array}{lcc}\text { Subgroup } & \text { Dark } & \text { Light } \\ \text { Admission type } & & \\ \text { Medical } & 12 / 47 & 8 / 75 \\ \text { Surgical } & 5 / 30 & 3 / 27 \\ \text { Sepsis } & & \\ \text { Yes } & 13 / 50 & 6 / 68 \\ \text { No } & 4 / 27 & 5 / 34 \\ \text { PaO2/FiO2 at admission } & \\ \geq 300 & 2 / 26 & 7 / 37 \\ <300 & 15 / 51 & 4 / 65\end{array}$

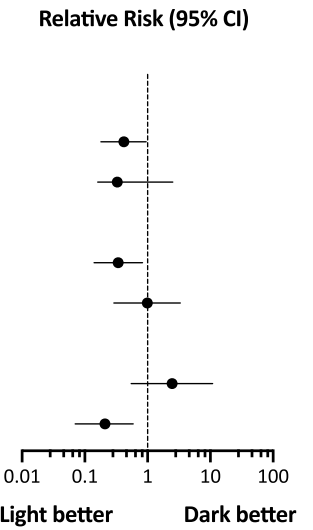

$P$ value for

heterogeneity

0.90

$0.42(0.18-0.95)$

$0.33(0.16-2.53)$

$0.34(0.14-0.83)$

$0.99(0.29-3.34)$

0.23

$<0.01$

$2.46(0.55-10.9)$

$0.21(0.07-0.59)$

Light better

Dark better

\section{Antipsychotics}

$\begin{array}{lcc}\text { Subgroup } & \text { Dark } & \text { Light } \\ \text { Admission type } & & \\ \text { Medical } & 15 / 47 & 13 / 75 \\ \text { Surgical } & 4 / 30 & 0 / 27 \\ \text { Sepsis } & & \\ \text { Yes } & 15 / 50 & 11 / 68 \\ \text { No } & 4 / 27 & 2 / 34 \\ \text { PaO2/FiO2 at admission } & \\ \geq 300 & 2 / 26 & 0 / 37 \\ <300 & 17 / 51 & 13 / 65\end{array}$

Relative Risk (95\% Cl)

$P$ value for

heterogeneity

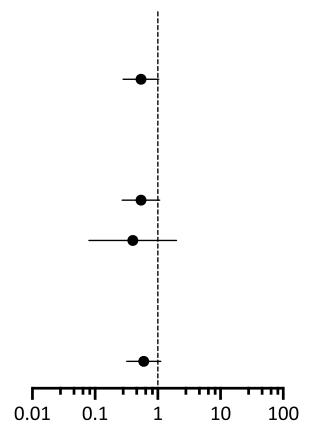

0.08

$0.54(0.28-1.04)$

NA

0.16

$0.54(0.27-1.07)$

$0.40(0.08-2.00)$

0.23

NA

$0.60(0.32-1.12)$

Light better Dark better

Fig. 1 Effects of admission to a room with natural light exposure on delirium outcomes, post hoc subgroup exploratory analyses. a Delirium, measured on the intensive care delirium screening checklist (ICDSC); $\mathbf{b}$ hallucinations item of the ICDSC; $\mathbf{c}$ severe agitation episodes intervened with antipsychotics during ICU stay. LIGHT indicates admission to a room with natural light exposure via windows. DARK indicates admission to a room without natural light exposure. ICU intensive care unit 


\section{Acknowledgements}

The authors thank HUPNVS (Hôpitaux Universitaires Paris Nord Val de Seine) for their support. The authors thank the nurses of the intensive care unit who participated in the study.

\section{Authors' contributions}

RS wrote the manuscript. RS and EM carried out the statistical analysis and interpreted the patient data. RSm, CD, LB, and JFT revised the manuscript. All authors read and approved the final manuscript.

\section{Funding}

None.

\section{Availability of data and materials}

The datasets used and/or analyzed during the current study are available from the corresponding author on reasonable request.

Ethics approval and consent to participate

The study was approved by the local ethics committee.

\section{Consent for publication}

Not applicable.

\section{Competing interests}

The authors declare that they have no competing interests.

\section{Author details}

${ }^{1}$ Université de Paris, INSERM UMR1 148, team 6, 75018 Paris, France. ${ }^{2}$ Department of Intensive Care Medicine and Infectious Diseases, AP-HP, Bichat-Claude
Bernard Hospital, 46 Rue Henri Huchard, 75018 Paris Cedex, France. ${ }^{3}$ Medical Intensive Care Unit, Gabriel Montpied University Hospital, Clermont-Ferrand, France. ${ }^{4}$ Université de Paris, INSERM UMR1 137, team 5, 75018 Paris, France.

Received: 28 January 2020 Accepted: 18 February 2020

Published online: 27 February 2020

\section{References}

1. Smonig R, Magalhaes E, Bouadma L, Andremont O, de Montmollin E, Essardy F, et al. Impact of natural light exposure on delirium burden in adult patients receiving invasive mechanical ventilation in the ICU: a prospective study. Ann Intensive Care. 2019;9:120.

2. Vahedian-Azimi A, Bashar FR, Khan AM, Miller AC. Natural versus artificial light exposure on delirium incidence in ARDS patients. Ann Intensive Care. 2020;10:15.

3. Kohn R, Harhay MO, Cooney E, Small DS, Halpern SD. Do windows or natural views affect outcomes or costs among patients in ICUs? Crit Care Med. 2013:41:1645-55.

\section{Publisher's Note}

Springer Nature remains neutral with regard to jurisdictional claims in published maps and institutional affiliations.

\section{Submit your manuscript to a SpringerOpen ${ }^{\odot}$ journal and benefit from:}

- Convenient online submission

- Rigorous peer review

- Open access: articles freely available online

- High visibility within the field

- Retaining the copyright to your article 